\title{
FILOSOFIA POLIÍTICA, DIREITOS HUMANOS E LUTAS MINORITÁRIAS: ALGUMAS BREVES E SUMÁRIAS CONSIDERAÇÕES.
}

\author{
Sylvio Gadelha ${ }^{1}$
}

RESUMO: O artigo centra-se na problemática que enlaça biopolítica, direito e resistência em nosso presente, limitando-se, contudo, a tecer apenas algumas breves e sumárias considerações sobre filosofia política, direitos humanos e lutas minoritárias. Inicia levantando algumas questões consideradas relevantes para que se possa pensar, no que tange a essa problemática, possíveis implicações da educação. Tomando como exemplo o caso das manifestações que varreram as ruas do Brasil, de junho a outubro do ano passado, assim como alguns efeitos dos protestos contra a Realização da Copa do Mundo em 2014, tais indagações questionam o modo como os movimentos minoritários concebem o papel do direito em suas lutas políticas de resistência. Trata-se de sondar, mais especificamente, se tais movimentos privilegiam uma ação política que valoriza, por exemplo, os direitos humanos (via jurídico-política) como estratégia importante em suas lutas políticas de resistência, ou se, ao contrário, se eles demonstram não apostar muito num ativismo de cunho jurídico-político e/ou jurídicofilosófico. Em seguida, levanta a possibilidade de a referida problemática vir a ser explorada mediante um diálogo inventivo e, talvez, inusitado, com filósofos como Michel Foucault e Gilles Deleuze, os quais não costumavam demonstrar maiores entusiasmos com as lutas em favor dos direitos humanos. Levanta-se também a possibilidade de que alguns impasses aí observados talvez se devam ao fato de a relação entre biopolítica, direito e resistência ser comumente abordada por um tipo de análise filosófico-política ancorada na representação clássica, motivo pelo qual comenta algumas formulações de Norberto Bobbio sobre filosofia política, poder e política, tomando esse autor como um exemplo de desvalorização de uma micropolítica.

PALAVRAS-CHAVE: biopolítica, direitos humanos, movimentos minoritários.

KEYWORDS: Biopolitic, human rights, minority movements.

MOTS-CLÉS: Biopolitique, droits de l'homme, mouvements minoritaires.

\footnotetext{
${ }^{1}$ Doutor em Educação pela Universidade de São Paulo e professor adjunto do departamento de Educação da Universidade Federal do Ceará (FACED/UFC).
} 
Nos rastros de minhas inquietações diante de problemas relativos à biopolítica em nosso presente, principalmente na medida em que os mesmos ressoam de algum modo junto à educação, tenho me dedicado de um tempo para cá a explorar relações entre biopolítica, direitos humanos e lutas políticas minoritárias, num exercício que almeja conjugar filosofia política e filosofia da educação. Em última instância, a questão maior que subjaz a esse esforço, como se pode depreender, diz respeito ao lugar e ao papel reservados ao direito na gestão biopolítica do vivo em nossa contemporaneidade. Sem que me proponha aqui a isso, supondo que se consiga responder, mesmo que de forma incipiente, a essa questão, dada sua amplitude e complexidade, uma segunda não menos importante se coloca àqueles que se ocupam da educação, a qual, por sua vez, remete ao modo como se julga conveniente e produtivo, quer seja para fins de análise, quer seja visando ao exercício propriamente dito da política, ou seja, do ativismo político, articular a educação a esse problema que envolve a tríade biopoder, direito e vida. Meu intuito consiste apenas em tecer algumas breves e sumárias considerações sobre fatores implicados, em maior ou menor medida, tanto a essas duas questões como a essa tríade.

O grego Costas Douzinas (2009), de um lado, e os brasileiros José Augusto Lindgren Alves (2005) e José Damião de Lima Trindade (2011), de outro, estão entre os vários estudiosos sérios para quem, em nossa contemporaneidade, os Direitos Humanos constituem um misto de tema e problema atravessado por um cruel paradoxo. Se desde a segunda metade do século XX eles foram consagrados mundialmente, ao ponto de virarem uma quase unanimidade para a maioria dos Estados-Nação, que em número crescente com eles vieram a se comprometer, por outro lado, de lá para cá, e simultaneamente, nunca foram tão solenemente ignorados, para não dizer desmoralizados e achincalhados. Em nossos dias, Ucrânia, Iraque, Sudão e Gaza são alguns dos cenários em que esse paradoxo se mostra em toda a sua magnitude, ao passo que Putin, Obama e Netanyahu constituem alguns de seus principais protagonistas. Alves (2005, p. 09) traça de forma concisa algumas das principais faces com que se manifesta esse paradoxo:

Filhos legítimos da modernidade e herdeiros presuntivos da Ilustração, os direitos humanos vivem situação contraditória nesta fase da "pósmodernidade". Adquiriram inusitada força discursiva, mas são ameaçados de todos os lados. Afirmaram-se como balizas da legitimidade institucional, mas sofrem rudes golpes da globalização econômica. Fortaleceram-se na ciência política e são quase que descaracterizados pela filosofia epistemológica. 
Receberam, da Conferência Mundial de Viena de 1993, o selo governamental do universalismo em época de grande exacerbação dos particularismos.

Trindade (2011, p. 15), por sua vez, apresenta esse paradoxo nos seguintes termos:

\begin{abstract}
Desde que os revolucionários franceses, a partir de 1879, passaram a proclamar aos quatro ventos sua Declaração dos Direitos do Homem e do Cidadão, a ideia de "direitos humanos", malgrado contramarchas, só ganhou respeitabilidade, a ponto de hoje desfrutar de quase unanimidade mundial -, o que, com certeza, nada nos informa quanto ao modo como, em cada canto desse vasto mundo, essa teoria faz seu salto para a prática, ou mesmo o que significa, na prática, esse salto. Talvez não tenha havido opressor nos últimos duzentos anos, ao menos no Ocidente, que não tivesse, em algum momento, lançado mão da linguagem dos direitos humanos. Hitler foi apenas mais um a adotar esse procedimento.
\end{abstract}

Costas Douzinas (2009), por seu turno, diz que no ocaso do século XX os direitos humanos foram tanto objeto de um sequestro como de uma morte anunciada. Eles teriam sido sequestrados, diz o autor (2009, p. 16), por "governos cientes dos benefícios de uma política moralmente confiável", ao passo que sua morte, prossegue ele (2009, p. 13), teria sido decretada devido ao desaparecimento do fim utópico que até então lhes servia de móvel (2009, p. 13):

Os direitos humanos perdem seu fim (...) quando deixam de ser o discurso e a prática da resistência contra a dominação e a opressão públicas e privadas para se transformar em instrumentos de política externa das grandes potências do momento, a "ética" de uma "missão civilizatória" contemporânea que espalha o capitalismo e a democracia nos rincões mais escuros do planeta.

Triunfo, de um lado; fracasso, de outro: os direitos humanos, portanto, parecem servir como precioso instrumento às lutas contra a exploração e as desigualdades socioeconômicas e político-culturais, mas também se prestam ao mesmo tempo às piores instrumentalizações políticas possíveis. No diagnóstico feito por Costas Douzinas, pelo menos parte desse problema se deve a uma dupla inadequação, a qual envolve tanto a política liberal como a filosofia do direito. Sigamos a curiosa argumentação do autor (2009, p. 15-16):

Embora os direitos representem uma das mais nobres instituições liberais, a política liberal e a filosofia do direito parecem incapazes de compreender a sua ação. Parte do problema deriva de um senso histórico e de uma consciência política dos liberais deploravelmente inadequados. $\mathrm{O}$ mundo em que habitam é um lugar atomocêntrico, constituído por contratos sociais e posturas originais motivados pela cegueira subjetiva dos véus da ignorância, 
atribuídos a situações de discursos ideais que retornam a uma certeza prémoderna de respostas corretas únicas a conflitos morais e jurídicos. Igualmente, o modelo de pessoa que povoa este mundo é o de um indivíduo autocentrado, racional e reflexivo, um sujeito autônomo kantiano, desvinculado de classe, raça, ou gênero, sem experiências inconscientes ou traumáticas e que se encontra no perfeito domínio de si mesmo, pronto a usar os direitos humanos para adequar o mundo aos seus próprios fins. Os melhores filósofos liberais da direita escrevem como se duzentos anos de filosofia e teoria social não tivessem acontecido, como se eles nunca tivessem ouvido falar de Marx e de lutas sociais, de Nietzsche, do poder e da resistência de Foucault, de Freud, da psicanálise e da dialética do desejo, ou de Levinas, Derrida e da ética da alteridade. A precariedade da filosofia política liberal e da jurisprudência é extraordinária e pode não estar totalmente desvinculada das nossas catástrofes recentes.

Atendo-me à nossa realidade, se considerarmos, por exemplo, desdobramentos recentes das intensas manifestações de rua que ocorreram originalmente de junho a outubro do ano passado, episódios que nesse ano de 2013 envolveram protestos contra a realização da copa do mundo e, logo depois, a criminalização dos mesmos, resultando inclusive em prisões arbitrárias de alguns ativistas, polêmicas e divisão da opinião pública, poder-se-ia indagar: como os movimentos minoritários, progressistas, ou de esquerda implicados diretamente em tais manifestações de protesto, concebem o direito, bem como suas relações com a política, com o Estado, com o exercício do poder, e com a segurança?

A essa indagação, poder-se-ia acrescentar outras duas, a saber: em primeiro lugar, como esses mesmos movimentos concebem a relação entre direito e resistência (por exemplo, a resistência que eles acreditam fazer, materializar, e/ou dar expressão, ao ocuparem as ruas; resistência que, ao que tudo indica, estende-se a um neocapitalismo excludente e aos modos de vida que ele secreta)? Em segundo lugar, no caso de haver um papel estratégico reservado à educação nessa relação entre direito e resistência política, que papel será esse e que tipo de educação tais movimentos têm em vista? Em outras palavras, trata-se de saber se tais movimentos mantém uma relação de confiança para com o direito e o Estado, quer dizer, para com as instituições encarregadas da normatividade jurídica e responsáveis pela aplicação das leis, da justiça, das políticas sociais, assim como responsáveis pela manutenção da ordem e da segurança, ao ponto de privilegiarem, como efeito dessa confiança, como sintoma dessa aposta, uma via jurídico-política de ação às suas lutas políticas minoritárias. Em outras palavras: será que tais movimentos tendem a valorizar uma modalidade jurídico-política de luta em seu ativismo político, ou será que, diversamente, cultivam, em relação ao direito e ao Estado, sentimentos e posições ambíguos que vão do medo e da desconfiança radical à

\begin{tabular}{|l|l|l|l|l|}
\hline Qonista Dialectus & Ano 2 & n.5 & Agosto - Dezembro 2014 & p. 98 - 110 \\
\hline
\end{tabular}


aposta de que, no fim das contas, e apesar de tudo, a justiça, a igualdade e a emancipação talvez possam ser conquistadas através de uma via eminentemente jurídica, como no caso das reivindicações em favor dos direitos humanos?

De início, sem que tivesse uma ideia clara do que desejava fazer, do tipo de investigação que gostaria exatamente de realizar, possuía, contudo, pelo menos a consciência de que se desenhava a mim uma ampla, complexa e longa pesquisa, a qual, remetendo-me ao âmbito onde se cruzam a filosofia política e a filosofia do direito, deveria permitir-me não só abordar a problemática em tela, mas também servir-me de pretexto para que eu tornasse a me aproximar, talvez de maneira inusitada, dos pensamentos de Gilles Deleuze e de Michel Foucault, com quem venho trabalhando nos últimos anos.

Em outros termos, tal pesquisa deveria tornar possível, dentre outras coisas, que eu realimentasse uma conversação construtiva com esses dois filósofos que me são muito caros, mas, agora, todavia, alterando o tema desse diálogo com ambos. O desafio consistiria, em primeiro lugar, em posicionar Deleuze e Foucault em face, de um lado, da doutrina do Direito Natural, e, de outro, das lutas políticas que, de certo tempo para cá, lançam suas principais apostas na defesa e garantia dos direitos humanos. Em segundo lugar, esse desafio consistiria em extrair desses dois filósofos maneiras outras não só de conceber o direito, mas também modos distintos de com ele nos relacionarmos, ou melhor, de o acionarmos em nossa defesa, em nossas lutas políticas de resistência, na condição de governados.

Em que sentido, todavia, tal reaproximação se mostraria, talvez, inusitada? Em termos provisórios, em primeiro lugar, digo que ela o seria no sentido de ambicionar explorar e problematizar algo que, pelo menos aparentemente, parece não ter empolgado muito a esses dois filósofos nem se revestido de maior importância para ambos, a saber: os direitos humanos. Ou seja, isso se daria pelo fato de que nem um nem outro se dedicaram com afinco, e de forma demorada, em seus respectivos trabalhos, a explorar questões relativas ao direito e à norma jurídica (o que vale especialmente para Deleuze). Em segundo, e em consonância e continuidade ao que foi dito acima, pelo fato de ambos expressarem, cada um a seu modo, e em maior ou menor medida, certa impaciência, senão má vontade diante desse tipo de ativismo, talvez pelo fato de estar ele significativamente atravessado por moralismos de toda sorte, do que é testemunha a disseminação, por entre o campo dos novos movimentos sociais, desde aproximadamente o início dos anos 1990, de uma cultura do politicamente correto,

\begin{tabular}{|l|l|l|l|l|}
\hline Q Ronista Dialectus & Ano 2 & n.5 & Agosto - Dezembro 2014 & p. 98 - 110 \\
\hline
\end{tabular}


cultura essa particularmente forte e presente no âmbito das lutas políticas vinculadas à defesa da diversidade e à defesa dos direitos humanos. Mas, impaciência, também, devido ao fato desse ativismo, no mais das vezes, operar com uma concepção jurídicopolítica, ou jurídico-filosófica do poder. De todo o modo, uma primeira incursão minha a essa questão foi apresentada no III Colóquio de Biopolítica: Violência e Estado de Exceção, realizado em Goiânia, em dezembro de 2012, numa palestra intitulada Estado de exceção e direito dos governados, posteriormente publicada na Revista de Filosofia Aurora. $^{2}$ Tendo isso em vista, volto a dizer que o que eu gostaria de dar a partilhar, daqui por diante, são algumas poucas ideias, ainda muito verdes e sumárias, além de carentes de uma melhor articulação, em todo o caso, algumas ideias que remetem ao título desta minha apresentação.

Penso que, talvez, um bom enfrentamento das questões anteriormente levantadas requeira de nós que as pensemos sem que para isso recorramos a uma imagem de pensamento - para falar com Deleuze - que, assim como sucede em outros domínios, tem se mostrado dominante na filosofia do direito desde há muito tempo. Nesse sentido, um bom enfrentamento dessas questões talvez requeira que as consideremos em suas implicações noológicas, ou seja, problematizando a imagem de pensamento hegemônica no cruzamento entre, de um lado, a filosofia do direito, e, de outro, a filosofia política e a ciência política. Em outras palavras, talvez um bom encaminhamento dessas questões diga respeito tanto à forma como concebemos o exercício do pensamento ( $1^{\circ}$ ponto) quanto ao modo como concebemos o exercício do direito e da política ( $2^{\circ}$ ponto). Refira-se, pois, tanto à imagem de pensamento que adotamos, quanto, além disso, ao modo como, a partir desta imagem adotada, concebemos a política, o direito e o exercício de ambos.

Nesse sentido, se fizermos uso de uma imagem de pensamento que é a da representação clássica, e se, além disso, a partir dessa imagem, fizermos uso de uma concepção de política, de uma concepção de poder e de uma concepção de direito que são aquelas consagradas tanto na ciência política quanto na filosofia política, a

\footnotetext{
${ }^{2}$ GADELHA, Sylvio. Estado de Exceção e Direito dos Governados. In: Revista de Filosofia Aurora (PUC-PR) - Dossiê Política e Biopolítica. Curitiba: PUC-PR, Jul. / Dez. 2013, v. 25 n. 37, pp. 107-130, ISSN $0104-4443$ (e ISSN $1980 \quad-\quad 5934) /$ Disponível em: http://www2.pucpr.br/reol/index.php/RF?dd1=12320\&dd99=view.
}

\begin{tabular}{|l|l|l|l|l|}
\hline Rovista Dialectus & Ano 2 & n.5 & Agosto - Dezembro 2014 & p. 98 - 110 \\
\hline
\end{tabular}


problematização de nosso tema deverá seguir determinada direção. Por falta de espaço não vou poder aqui examiná-la mais demoradamente, limitando-me apenas a assinalar que, para todos os efeitos, essa via não têm se mostrado nem muito produtiva nem sensível às transformações e aos desafios atuais, particularmente à crise e ao esvaziamento das instituições sociais e políticas e, complementarmente, aos clamores contundentes por mudanças socioculturais e político-econômicas, clamores esses espalhados por todo o mundo, inclusive, marcando sua presença no Brasil. Mas, se, em vez disso, fizermos uso de um pensamento outro, sem imagem (traduzido, aqui, pelas filosofias da diferença, do acontecimento e das multiplicidades), e se, além disso, concebermos a política sob uma perspectiva micropolítica, arqueogenealógica e biopolítica, conforme pensadas, respectivamente, por Deleuze e Guattari, e por Foucault, a abordagem de nosso problema deverá seguir uma direção bem distinta, talvez, bem mais potente, mesmo sem que saibamos de antemão aonde iremos chegar e se teremos ou não êxito em nossas investigações.

Vejamos, contudo, um exemplo do que se passaria no primeiro caso. Num texto em que aborda as possíveis relações entre Filosofia Política e Ciência Política, Norberto Bobbio (2003) distingue quatro significados diferentes para o termo Filosofia Política. No primeiro caso (Bobbio, 2003, p. 58), pode-se entendê-la como a “descrição, projeção e teorização da república perfeita, ou, se preferirmos, como a construção de um modelo ideal de Estado baseado em alguns postulados éticos fundamentais, sem nos preocupar quando e como ele poderá ser efetiva e totalmente realizado." No segundo caso (Idem, p. 58 - grifo do autor), pode-se considerá-la como a...

busca do fundamento último do poder, que permite responder às perguntas 'a quem devo obedecer?' e 'por quê?'. Trata-se do problema, bastante conhecido, da natureza e da função da obrigação política. Nesta acepção, a filosofia política conduz à solução do problema da justificação do poder último ou, em outras palavras, à determinação de um ou mais critérios de legitimidade do poder.

No terceiro caso (Bobbio, 2003, p. 58), por sua vez, o sentido de filosofia política é o de...

determinação do conceito geral de 'política' como uma atividade autônoma, um modo ou forma do espírito - como diria um idealista - que tem características peculiares, as quais a distinguem da ética e da economia, do direito e da religião. Da mesma maneira, diz-se que a tarefa da filosofia do direito é determinar o conceito de direito. 
Quanto a essa acepção do termo, Bobbio (2003, p. 59) acrescenta o seguinte comentário:

\begin{abstract}
Quando se fala de filosofia política entre nós, o pensamento busca imediatamente não tanto o problema da obrigação política, como ocorreria no caso de um estudioso inglês, mas sim o problema da distinção entre política e moral, entre razão individual e razão de Estado, o problema de se a conduta política possui suas próprias leis, se responde a critérios de valor próprios, se os fins justificam os meios, se os Estados podem ser governados com orações ou, como se diria hoje, se há uma ética de grupo distinta da ética individual, ou ainda, conforme a terminologia weberiana, se o homem político segue a ética da responsabilidade ou a das convicções, etc.
\end{abstract}

No quarto e último caso, por seu turno, Bobbio (2003, p. 59 - grifo do autor) afirma que o sentido de filosofia política assume um caráter eminentemente epistemológico, podendo ser entendida como...

\begin{abstract}
discurso crítico, construído sobre pressupostos, condições de verdade, pretensões de objetividade, ou não-valoração, da ciência política. Dessa perspectiva, poder-se-ia falar de filosofia política como metaciência, ou seja, como um estudo da política em um segundo nível, que não é o nível direto da investigação científica, entendida como o estudo empírico dos comportamentos políticos. Trata-se do nível indireto da crítica e da legitimação dos procedimentos por meio dos quais se realiza a investigação no primeiro nível. Nessa perspectiva entra a orientação da filosofia analítica, que aponta para a dissolução da filosofia política na análise da linguagem política.
\end{abstract}

Se acontecer de optarmos por nos debruçar sobre a relação entre política e direito a partir da perspectiva sugerida por Bobbio, talvez, então, antes de falarmos em filosofia política, seja conveniente que nos ocupemos, mesmo que de forma breve, do sentido que ele atribui à própria política. Nesse caso, o autor afirma (2003, p. 139) que esse termo é normalmente empregado para designar "a esfera das ações que têm relação direta ou indireta com a conquista e o exercício do poder último (supremo ou soberano) sobre uma comunidade de indivíduos em um território". Além disso, para determinarmos o âmbito abrangido pela política, assevera Bobbio (2003, p. 139), não podemos deixar de lado...

as relações de poder que em toda sociedade se estabelecem entre indivíduos e grupos, entendendo-se poder como a capacidade de um sujeito influir, condicionar e determinar o comportamento de outro indivíduo. O vínculo entre governantes e governados, no qual se dissolve a relação política principal, é uma relação típica de poder.

O poder exercido na pólis, que é aquele exercido pelos governantes sobre os governados, é o poder propriamente político. Importa reter, sobretudo, que, para 
Bobbio, a definição de política só é possível na medida em que envolva o exercício do poder e, especialmente, de um poder, que, à diferença do poder paternal (do pai sobre os filhos) e do poder patronal (do senhor sobre seus escravos), seja caracterizado como um poder propriamente político. Cabe indagar, todavia, se essa maneira de se conceber a política, isto é, de pensá-la como constituindo o âmbito das ações que têm relação direta, ou indireta com a conquista e o exercício do poder último (supremo ou soberano) sobre uma comunidade de indivíduos em um território, se mostra realmente produtiva, e por isso considero que vale a pena deter-me um pouco mais no assunto.

Por um lado, o filósofo nos diz que a esfera de atuação da política envolve ações que têm relação direta ou indireta com a conquista e o exercício do poder último (supremo ou soberano) sobre uma comunidade de indivíduos em um território; por outro lado, ele nos diz que, para bem apreendermos o que consiste a política, não podemos prescindir das relações de poder que em toda sociedade se estabelecem entre indivíduos e grupos, entendendo-se poder como a capacidade de um sujeito influir, condicionar e determinar o comportamento de outro indivíduo. Dito isso, não haveria algo de problemático nessa formulação de Bobbio? Parece-me que sim, e esse elemento problemático tem a ver com o modo como nela comparecem o macro e o micro, ou, para falar com Deleuze e Guattari, as dimensões molar e o molecular da política.

Com efeito, Bobbio parece dizer que a política tem como referência o Estado, tomado aqui como um universal necessário à vida social, como entidade unificada e transcendente ao corpo social e, ainda, como fim a ser alcançado pelas ações ou pelas lutas políticas. Nessa linha argumentativa, fazer política é lutar pela conquista do poder soberano, desse poder último, que não é outro senão o poder de Estado. A esse propósito, poder-se-ia indagar se os milhares de manifestantes que saíram às ruas no ano passado em várias cidades do Brasil, certamente exercendo a política, seja calmamente, seja através de práticas violentas, tinham como fim, como afirma Bobbio, a conquista do poder de Estado.

O curioso, no entanto, é que, em seguida, Bobbio nos diz que, para compreendermos o âmbito abrangido pela política, não podemos deixar de lado as relações de poder que em toda sociedade se estabelecem entre indivíduos e grupos, entendendo-se por poder, no caso, a capacidade de alguém de influir, condicionar e determinar o comportamento de outrem. Aqui, como se pode notar, Bobbio parece sair de um prisma de análise macrossocial e dirigir-se para uma forma de análise que privilegia o microssocial, salientando, por exemplo, as ações que os indivíduos exercem

\begin{tabular}{|l|l|l|l|l|}
\hline Q Ronista Dialectus & Ano 2 & n.5 & Agosto - Dezembro 2014 & p. 98 - 110 \\
\hline
\end{tabular}


uns sobre os outros. Assim, nessa direção, seria interessante explorar a hipótese de que Bobbio se serve de uma imagem de pensamento que é a da representação clássica para pensar a relação entre direito e política, e que, em assim o fazendo, sua apreensão da política, do poder e da relação entre política e direito, se dá por intermédio do que Foucault chamou, no curso Em defesa da sociedade, de uma concepção jurídico-política e/ou jurídico-filosófica do poder. Ora, em se adotando tal perspectiva analítica, tudo concorre para que nela a dimensão molar seja valorizada, em detrimento, simultaneamente, de uma micropolítica e de uma microfísica do poder.

Dito isto, podemos nos ocupar agora do que se passa nesse caso, ou seja, o da imagem do pensamento designada por representação clássica. Seguindo a orientação deixada por Deleuze, Regina Shöpke (2004, p. 25-26 - grifos da autora), afirma que os pressupostos básicos, ou postulados implícitos pelos quais a identificamos são, respectivamente, os seguintes:

O pensamento se exerce "naturalmente", como unidade de todas as outras
faculdades, consideradas seus modos. Tem uma boa natureza e uma boa
vontade. Goza de uma natureza reta que tende para a verdade, considerada
um universal abstrato. A verdade absoluta é buscada e amada pelo pensador,
sujeito de "boa vontade" e de princípios indiscutíveis. É pelo 'bem' que o
filósofo dedica sua existência ao supremo ato do pensamento.

Existiriam forças avessas ou estranhas ao pensamento, que acabariam por impedir o seu perfeito e natural funcionamento. Essas forças, advindas do corpo, das paixões, ou de qualquer interesse sensível, desviam o pensamento de seu objeto específico, fazendo-o tomar o falso pelo verdadeiro. O erro é, dessa forma, visto como o efeito dessas forças que atuam sobre o pensamento, restando ao filósofo o exercício de uma prática ascética de "insensibilização", de mortificação do corpo.

Necessitamos de um método que nos leve a pensar verdadeiramente, que nos dirija retamente ao conhecimento pleno da verdade. Só um método rigoroso pode conjurar definitivamente o "erro". Somente por meio desse método experimentaremos a certeza de que, independentemente de momento e lugar, somos capazes de penetrar no domínio do que 'vale em todos os tempos e em todos os lugares.

Esses pressupostos básicos ou postulados implícitos da representação clássica não só revestem a filosofia de certa "inocência” que ela, de fato, não tem, mas também a impregnam de um caráter moralizador e de uma dóxa, a saber: a de que é óbvio o que significa pensar (“Todo mundo sabe que...”). Na verdade, diz Shöpke (2004, p. 26), “essa imagem do pensamento (...) reflete claramente o ideal moral da razão e da própria filosofia como 'ciência' do pensamento. Isso porque somente uma filosofia impregnada de valores morais admite a possibilidade de uma retidão do pensamento ou a ideia de 
um 'Bem' como seu fundamento." Para Deleuze, (1988, p. 219), de acordo com essa imagem, o pensamento "está em afinidade com o verdadeiro, possui formalmente o verdadeiro e quer materialmente o verdadeiro. E é sobre esta imagem que cada um sabe, que se presume que cada um saiba o que significa pensar". Em termos muito esquemáticos, estamos no âmbito da representação, quando:

1. Aceitamos que existe uma espécie de afinidade "natural" / espontânea entre o pensamento (a razão) e o real (as "essências"), afinidade esta que se busca representar mediante uma mútua adequação (por exemplo, em Hegel - "o real é racional");

2. Negligenciamos o jogo de forças desde o qual se produz uma imposição de sentido ao real, imposição esta que faz subsumir o caráter agonístico e arbitrário desse ato de impor uma significação, ou de se proceder a uma representação;

3. Quando negativamos e até mesmo excluímos da composição do real quaisquer elementos relativos à diferença, à contingência, à desordem e à multiplicidade, sob o pretexto de que as mesmas nos levariam necessariamente à desagregação e à destruição;

4. Quando tomamos o pensamento como regido pelo princípio moralista do dever-ser e por princípios apriorísticos, universais, abstratos, transcendentes e absolutos;

5. Quando, por fim, tomamos o pensamento como legislador (fundante, competente e legitimador) de quaisquer outras formas de saber (a filosofia e a epistemologia como metadiscursos de índole policialesca).

Essa imagem de pensamento da representação clássica condicionou, de certo modo, toda uma forma tradicional de se conceber o exercício do poder, isto é, fez com que tendêssemos a apreendê-lo e a concebê-lo desde uma perspectiva jurídico-política, e/ou jurídico-filosófica, tal como designada por Foucault no curso Em defesa da sociedade (1999). Ora, falar desde tal perspectiva significa falar do poder em termos de soberania, isto é, falar do poder soberano, tal como ele era exercido nas sociedades de soberania. Sem perder de vista nossas questões, vejamos o que seria importante reter da abordagem de Foucault sobre esse assunto e, muito sucintamente, quais os desdobramentos e efeitos que podem daí ser derivados.

Foucault (1999) busca desembaraçar a análise política do poder da tríade formada por poder, direito e verdade, isto é, da intensidade e constância com que esses três termos comparecem relacionados uns aos outros, na maior parte dos enunciados sobre esse tema, sejam eles da filosofia política, sejam da ciência política. O essencial dessa relação se encontra no seguinte trecho de Em defesa da sociedade (1999, p. 31): 
O papel essencial da teoria do direito, desde a Idade Média, é o de fixar a legitimidade do poder: o problema maior, central, em torno do qual se organiza toda a teoria do direito é o problema da soberania. Dizer que o problema da soberania é o problema central do direito nas sociedades ocidentais significa que o discurso e a técnica do direito tiveram essencialmente como função dissolver, no interior do poder, o fato da dominação, que se queria reduzir ou mascarar, duas coisas: de um lado, os direitos legítimos da soberania, do outro, a obrigação legal da obediência.

Com o intuito de escapar a essa redução ou dissimulação do fato da dominação, Foucault promove um duplo deslocamento em sua análise política do poder. Por um lado, ele inverte a direção da mesma, fazendo-a, então, partir inicialmente do domínio factual, isto é, das práticas, das técnicas e dos mecanismos mediante os quais o poder concretamente se exerce, para só depois, ao final, chegar à inteligibilidade de sua dimensão jurídico-política, ou jurídico-filosófica. Por outro lado, para além dessa atenção aos seus operadores materiais, ao modus operandi do poder, ou seja, para além do destaque por ele concedido ao modo como funciona, concreta e efetivamente, o poder, Foucault também inova ao privilegiar, em vez do problema que relaciona soberania e obediência, como era habitual, outro problema, que vincula, agora, a dominação à sujeição. Com efeito, para ele (1999, pp. 31-32 - grifos meus), trata-se de investigar...

\begin{abstract}
como, até onde e sob que formas, o direito (e quando digo o direito, não penso somente na lei, mas no conjunto dos aparelhos, das instituições, regulamentos que aplicam o direito) veicula e aplica relações que não são relações de soberania, mas relações de dominação. E, com dominação, não quero dizer o fato maciço de "uma" dominação global de um sobre os outros, mas as múltiplas formas de dominação que podem se exercer no interior da sociedade; não, portanto, o rei em sua posição central, mas os súditos em suas relações recíprocas; não a soberania em seu edifício único, mas as múltiplas sujeições que ocorreram e funcionam no interior do corpo social.
\end{abstract}

Ora, por qual razão creio ser importante reter particularmente esses dois pontos, da argumentação de Foucault? Pelo fato de que, somadas à ideia de que onde há poder há correlativamente resistência a este, tais formulações nos permitem, em consequência mesmo que indiretamente, na condição de governados, que deixemos de obedecer, que passemos a resistir, ou senão, ao menos a reivindicar um direito que seria propriamente nosso, o de não obediência, ou de resistência à dominação, à regulamentação, ao governo, ao governamento, ao controle e à modulação de nossas vidas. Como acionar a educação para potencializar o exercício desse direito, e que educação serviria a contento a esse propósito? Creio que tais indagações, uma vez agenciadas às que assinalei logo 
ao início do texto, podem servir como pistas a serem exploradas pelos eventuais interessados no assunto.

\section{Referências Bibliográficas}

ALVES, José Augusto Lindgren. Os Direitos Humanos na Pós-Modernidade. São Paulo: Perspectiva, 2005.

BOBBIO, Norberto. O Filósofo e a Política. Antologia. Organização e apresentação de José Fernandez Santillán. Prefácio de Norberto Bobbio. Rio de Janeiro: Contraponto, 2003.

COSTAS DOUZINAS. O Fim dos Direitos Humanos. São Leopoldo: Unisinos, 2009. DELEUZE, Gilles. Diferença e Repetição. Rio de Janeiro: Graal, 1988.

FOUCAULT, Michel. Em Defesa da Sociedade. Curso no Collège de France (19751976). São Paulo: Martins Fontes, 1999.

GADELHA, Sylvio. Estado de Exceção e Direito dos Governados. In: Revista de Filosofia Aurora (PUC-PR) - Dossiê Política e Biopolítica. Curitiba: PUC-PR, Jul. / Dez. 2013, v. 25 n. 37, pp. 107-130, ISSN 0104 - 4443 (e ISSN 1980 - 5934) / Disponível em: http://www2.pucpr.br/reol/index.php/RF?dd1=12320\&dd99=view.

SCHÖPKE, Regina. Por uma Filosofia da Diferença: Gilles Deleuze, o pensador nômade. Rio de Janeiro: Contraponto; São Paulo: Edusp, 2004.

TRINDADE, José Damião de Lima. 3a. ed. História Social dos Direitos Humanos. São Paulo: Peirópolis, 2011. 